\section{(6) OPEN ACCESS}

\title{
Randomised controlled trial of early frenotomy in breastfed infants with mild-moderate tongue-tie
}

\author{
Alan Emond, ${ }^{1}$ Jenny Ingram, ${ }^{1}$ Debbie Johnson, ${ }^{1}$ Peter Blair, ${ }^{1}$ Andrew Whitelaw, ${ }^{1}$ \\ Marion Copeland, ${ }^{2}$ Alastair Sutcliffe ${ }^{3}$
}

${ }^{1}$ University of Bristol, Bristol, UK

${ }^{2}$ Southmead Hospital, Bristol, UK

${ }^{3}$ University College London, London, UK

\section{Correspondence to} Professor Alan Emond, Centre for Child and Adolescent Health, School of Social and Community Medicine, University of Bristol, Oakfield House, Bristol BS8 2BN, UK alan.emond@bristol.ac.uk

Received 9 August 2013 Revised 14 October 2013 Accepted 15 October 2013 Published Online First 18 November 2013

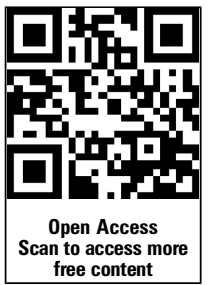

\section{SLinked}

- http://dx.doi.org/10.1136/ archdischild-2013-305493

To cite: Emond A, Ingram J,
Johnson D, et al. Arch Dis
Child Fetal Neonatal Ed
2014;99:F189-F195.

\section{ABSTRACT}

Trial design A randomised, parallel group, pragmatic trial.

Setting A large UK maternity hospital.

Participants Term infants $<2$ weeks old with a mild or moderate degree of tongue-tie, and their mothers who were having difficulties breastfeeding.

Objectives To determine if immediate frenotomy was better than standard breastfeeding support.

Interventions Participants were randomised to an early frenotomy intervention group or a 'standard care' comparison group.

Outcomes Primary outcome was breastfeeding at 5 days, with secondary outcomes of breastfeeding selfefficacy and pain on feeding. Final assessment was at 8 weeks; 20 also had qualitative interviews. Researchers assessing outcomes, but not participants, were blinded to group assignment.

Results 107 infants were randomised, 55 to the intervention group and 52 to the comparison group. Five-day outcome measures were available for $53(96 \%)$ of the intervention group and $52(100 \%)$ of the comparison group, and intention-to-treat analysis showed no difference in the primary outcome-Latch, Audible swallowing, nipple Type, Comfort, Hold score. Frenotomy did improve the tongue-tie and increased maternal breastfeeding self-efficacy. At 5 days, there was a $15.5 \%$ increase in bottle feeding in the comparison group compared with a $7.5 \%$ increase in the intervention group.

After the 5-day clinic, 44 of the comparison group had requested a frenotomy; by 8 weeks only $6(12 \%)$ were breastfeeding without a frenotomy. At 8 weeks, there were no differences between groups in the breastfeeding measures or in the infant weight. No adverse events were observed.

Conclusions Early frenotomy did not result in an objective improvement in breastfeeding but was associated with improved self-efficacy. The majority in the comparison arm opted for the intervention after 5 days.

\section{INTRODUCTION}

Ankyloglossia, or tongue-tie, a congenital condition characterised by a short, thickened or abnormally tight lingual frenulum, affects between $1.7 \%$ and $4.7 \%$ of all infants and is one of the causes of breastfeeding difficulties in early life. ${ }^{1-3}$ Feeding difficulties (both breast and bottle) have been reported in $12-44 \%$ of infants with tongue-tie ${ }^{1} 3-6$ due to a variety of reasons, including poor latch, nipple trauma and inability to feed continuously. Current 6-week breastfeeding rates in the UK remain around $55 \%{ }^{7}$ Many mothers want to breastfeed but give up

\section{What is known on this topic}

- Tongue-tie (ankyloglossia) is a common congenital condition which can interfere with breastfeeding.

- Tongue-tie release (frenotomy) is a well-tolerated procedure that can provide objective and subjective benefits in breast feeding.

- Evidence from randomised trials supports early frenotomy in severe cases of tongue-tie, but debate continues about management of mildmoderate degrees of tongue-tie resulting in wide variations in clinical practice.

\section{What this study adds}

A randomised, parallel group, pragmatic trial comparing early frenotomy with usual care in mild-moderate tongue-tie showed that mothers could sustain breastfeeding of infants with tongue-tie for 5 days without a frenotomy.

- Early frenotomy did not result in an objective improvement in breastfeeding at 5 days.

- Early frenotomy did improve maternal breastfeeding self-efficacy and resulted in fewer mothers switching to bottle feeding before 5 days.

due to experiencing problems and receive varying lactation support. Tongue-ties are a simple reversible cause of poor breastfeeding that can be managed by frenotomy, which is a relatively low risk and effective procedure. $^{8}$ However, debate continues about whether infants with tongue-tie should be offered immediate frenotomy, ${ }^{9}$ and there is wide variation in the availability of the procedure across the UK.

A recent systematic review ${ }^{10}$ concluded that tongue-tie release is a well-tolerated procedure that provides objective and subjective benefits in breast feeding, but that there were a limited number of studies available with quality evidence. Five prospective randomised controlled trials (RCTs) of frenotomy conducted between 2004 and $2012^{11-15}$ have together provided evidence of the effectiveness of frenotomy in the most severe degrees of tongue-tie, but more evidence is required before the procedure can be recommended for mild or moderate cases. 
We report a randomised feasibility trial of early frenotomy compared with usual care in infants with mild-moderate degrees of tongue-tie. The trial objectives were to determine if immediate frenotomy was better than usual breastfeeding support, and if mothers could sustain breast feeding of infants with tongue-tie for 5 days without frenotomy.

\section{METHODS}

\section{Study design}

This randomised, parallel group, single centre feasibility trial was undertaken between October 2011 and June 2013 at Southmead Hospital in Bristol, UK. This centre has an established service for treatment of tongue-tie led by midwife lactation consultants and good support for breastfeeding in the hospital and the community midwifery service in Bristol. The study was approved by the Central Bristol research ethics committee and conducted in accordance with Good Clinical Practice guidelines and the Declaration of Helsinki. Trial registration: ISRCTN 73554751. The study protocol is available at: http:/ www.bristol.ac.uk/ccah/research/nutritiondevelopment/ tonguetietrial.html

Independent trial oversight was provided by an independent trial steering committee.

\section{Study population}

Trial subjects were mothers from the Bristol area with term babies with a tongue-tie who were experiencing breastfeeding difficulties (typically, poor attachment and sore nipples). Eligibility was determined by one of two lactation consultants who observed a breast feed and used the Hazelbaker Assessment Tool for Lingual Frenulum Function ${ }^{16}$ (HATLFF-short form) to measure the degree of tongue-tie, and the Latch, Audible swallowing, nipple Type, Comfort, Hold (LATCH) Scale ${ }^{17}$ to assess breastfeeding. A comparison between the two lactation consultants using the HATLFF, based on 30 infants, produced an interclass correlation of 0.89 (95\% CI 0.77 to 0.94 ).

Breastfed babies were eligible for enrolment if the HATLFF score was 6-12 (indicating a mild-moderate tongue-tie) and the LATCH score was $\leq 8$. Exclusion criteria were infant age ( $>2$ weeks old), prematurity ( $<37$ weeks), congenital orofacial malformations and infant weight loss ( $>10 \%$ birth weight). Those with a severe tongue-tie (HATLFF score <6) were not eligible for randomisation and were offered immediate frenotomy.

\section{Randomisation and masking}

After giving written informed consent, mothers were randomised to an intervention arm and offered immediate frenotomy, or to a comparison arm and given the standard postnatal care offered in Bristol. Participants were block randomised equally to the two groups by an independent telephone-based randomisation service provided by Bristol Randomised Trials Collaboration, stratifying for sex of infant and birth order. All trial participants were offered routine breastfeeding support as provided by midwives as part of community postnatal care and reassessed at a special research clinic 5 days later. Mothers in the comparison arm who were still experiencing breastfeeding difficulties at the 5-day assessment were then given the option of frenotomy. The final trial assessment at 8 weeks was undertaken initially by telephone, and those who were still breast feeding were reassessed at home. Researchers collecting the outcomes, but not participant mothers, were blinded to infant group assignment.
Measuring tools used

The short-form HATLFF ${ }^{16}$ was used to measure the degree of tongue-tie. A score of $<6$ indicated a severe tongue-tie and 612 a moderate or mild tongue-tie.

The LATCH Scale ${ }^{17}$ was used for measuring breastfeeding effectiveness, and a score of $\leq 8$ indicated breastfeeding difficulties. A difference of one point on the LATCH $(=1.5 \mathrm{SD}$, effect size of 0.67 ) was considered to be clinically important.

The Infant Breast Feeding Assessment Tool (IBFAT) ${ }^{18}$ was added as a secondary outcome because it is more suitable for assessing breastfeeding behaviour of newborn infants.

The Breastfeeding Self-Efficacy score-short form (BSES-SF) ${ }^{19-22}$ was added as a secondary outcome to measure mother's confidence in her ability to breastfeed her new baby, in addition to an external observer's evaluation of breastfeeding effectiveness.

The Pain Visual Analogue Scale (VAS) was scored on a 0 $10 \mathrm{~cm}$ line, with 0 representing no pain and 10 the worst pain.

\section{Study outcomes}

The primary outcome was LATCH score at 5 days. Secondary breastfeeding outcomes were LATCH score at 8 weeks, and IBFAT score, BSES-SF and pain scale at 5 days and 8 weeks. Other outcomes of interest were HATLFF score at 5 days and infant weight at 8 weeks.

\section{Qualitative interviews}

At the 8-week contact, all mothers were invited to be interviewed by a qualitative researcher. From the 84 who agreed, a purposive sample of 20 was selected to include a range of feeding methods and ages of babies in both arms of the trial. The telephone interviews explored their views on the trial, the intervention process, the acceptability of randomisation and their attitude to frenotomy. They were digitally recorded, transcribed and analysed using standard thematic methods of building codes into themes and subthemes using the process of constant comparison. ${ }^{23}$

Table 1 Outcomes in intervention and comparison groups

\begin{tabular}{|c|c|c|c|}
\hline $\begin{array}{l}\text { Results at } 5 \text { days } \\
\text { (primary outcome } \\
\text { point) }\end{array}$ & $\begin{array}{l}\text { Intervention } \\
\mathrm{N}=53 \\
\text { median } \\
\text { (IQR) }\end{array}$ & $\begin{array}{l}\text { Comparison } \\
\mathrm{N}=52 \\
\text { median } \\
\text { (IQR) }\end{array}$ & $\begin{array}{l}\text { p Values (Mann- } \\
\text { Whitney tests) }\end{array}$ \\
\hline Infant age (days) & $11(8-14)$ & $11(8-16)$ & 0.94 \\
\hline LATCH score & $9(8-10)$ & $9(8-10)$ & 1.0 \\
\hline IBFAT score & $12(11-12)$ & $12(11-12)$ & 0.76 \\
\hline Self-efficacy score & $54(43-62)$ & $53(40.8-61)$ & 0.53 \\
\hline Pain VAS score & $3(1-4.3)$ & $3(2-6)$ & 0.13 \\
\hline HATLFF score & $13.5(11-16)$ & $8(7-11)$ & $<0.0001$ \\
\hline $\begin{array}{l}\text { Results at } 8 \text { weeks (trial } \\
\text { end) }\end{array}$ & $\begin{array}{l}\text { Intervention } \\
\mathrm{N}=52 \\
\text { median (IQR) }\end{array}$ & $\begin{array}{l}\text { Comparison } \\
\mathrm{N}=50 \\
\text { median (IQR) }\end{array}$ & $\begin{array}{l}\mathrm{p} \text { Values (Mann- } \\
\text { Whitney tests) }\end{array}$ \\
\hline Infant age (days) & $62(58-68)$ & $65(59-72)$ & 0.18 \\
\hline Infant weight (kg) & $5(5-6)$ & $5(5-6)$ & 0.54 \\
\hline LATCH score & $10(10-10)$ & $10(10-10)$ & 0.41 \\
\hline IBFAT score & $12(12-12)$ & $12(12-12)$ & 0.58 \\
\hline BSES & $63(59-68)$ & $63(57-69)$ & 0.62 \\
\hline Pain VAS score & $0(0)$ & $0(0-1)$ & 0.41 \\
\hline
\end{tabular}




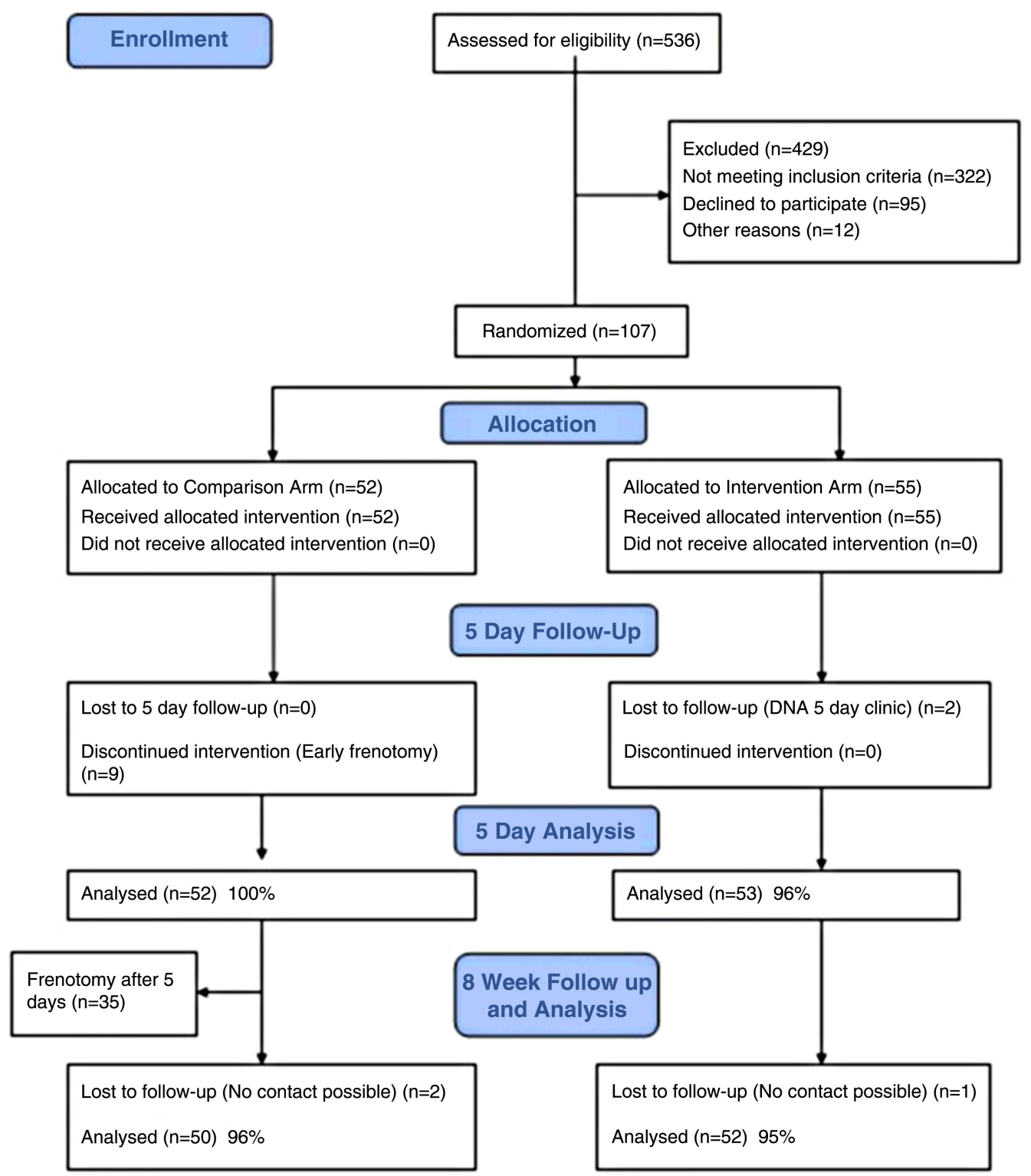

Figure 1 CONSORT flow diagram for Bristol Tongue Tie Trial.

\section{Statistical analysis}

To detect a change in LATCH score of 1 or more, at $90 \%$ power using the 5\% significance level, 50 mothers were required in each arm of the trial.

All analyses were conducted according to the intention-to-treat principle. The continuous data were not normally distributed, so non-parametric methods were used to test for differences between the two groups. Median and IQRs (25th and 75th centiles) have been used and the Mann-Whitney test as an equivalent to the Student $t$ test. For categorical data, the $\chi^{2}$ test was used or the Fisher's exact test (when an expected cell was less than 5). Significance was set at the $5 \%$ level.

\section{RESULTS}

\section{Recruited sample}

Mothers and infants were recruited from October 2011 to March 2013 following referral by a hospital or community midwife to the lactation consultants at Southmead Hospital. In total, 107 infants were randomised to the study, 55 in the intervention group and 52 in the control group. The baseline demographic characteristics of the two groups were very similar, but compared with the general profile of women delivering at Southmead hospital, trial mothers had a higher educational level and were less likely to come from an ethnic minority background. Of the 429 women with breastfeeding difficulties who were assessed for eligibility but were not enrolled (see Consolidated Standards of Reporting Trials (CONSORT) flow chart figure 1), the most common reason $(206 ; 48 \%)$ was the baby was too old ( $>2$ weeks). For $84(20 \%)$, the tongue-tie was too severe (HATLFF score $<6$ ) and the mother was offered frenotomy outside the trial. Of the 95 women who met the inclusion criteria but refused to be randomised, nearly half wanted the frenotomy straight away (these were women who had had a previous infant with tongue-tie), and a third preferred to 'wait and see' how breast feeding progressed. The baseline breastfeeding profiles of the intervention and comparison groups were similar.

\section{Primary outcome}

Table 1 provides the results at 5 days. All 55 infants allocated to the intervention received immediate frenotomy, but two did not 
Table 2 Changes in scores from baseline to 5 days and from 5 days to 8 weeks

\begin{tabular}{|c|c|c|c|}
\hline & $\begin{array}{l}\text { Intervention } \\
\mathrm{N}=53 \\
\text { (median, IQR) }\end{array}$ & $\begin{array}{l}\text { Comparison } \\
\mathrm{N}=52 \\
\text { (median, IQR) }\end{array}$ & $\begin{array}{l}\mathrm{p} \text { Values } \\
\text { (Mann-Whitney tests) }\end{array}$ \\
\hline \multicolumn{4}{|l|}{ HATLFF score } \\
\hline $0-5$ days & $4.5(3.3-6)$ & $0(0-2.3)$ & $<0.0001$ \\
\hline \multicolumn{4}{|l|}{ LATCH score } \\
\hline $0-5$ days & $1(0-2)$ & $1(0-2)$ & 0.52 \\
\hline \multicolumn{4}{|l|}{ IBFAT score } \\
\hline $0-5$ days & $0(-1.8$ to 1.0$)$ & $0(0-1)$ & 0.36 \\
\hline \multicolumn{4}{|l|}{ BSES } \\
\hline $0-5$ days & 9 (1.8 to 12.3$)$ & $1(-4$ to +7.5$)$ & 0.002 \\
\hline 5 days -8 weeks & $3(0$ to 13$)$ & $10(2$ to 18$)$ & 0.082 \\
\hline \multicolumn{4}{|l|}{ Pain VAS score } \\
\hline $0-5$ days & $-2(-3$ to 0.4$)$ & $-1(13.5$ to 1$)$ & 0.09 \\
\hline 5 days- 8 weeks & $-2(-3$ to -1$)$ & $-2(-3.5$ to -0.6$)$ & 0.83 \\
\hline
\end{tabular}

attend the 5-day follow-up and the mothers could not be contacted. Of the 52 randomised to usual care in the comparison group, nine (17\%) mothers could not wait until 5 days (due to painful feeding) and requested early frenotomy. Five-day outcome measures were therefore available for 53 (96\%) of the intervention group and $52(100 \%)$ of the comparison group, and analysis showed no difference in the primary outcomeLATCH score.

\section{Secondary outcomes}

The intervention improved the tongue-tie, as shown by a significant increase in the HATLFF score, but the other breastfeeding measures (IBFAT and pain) were no different from those in the comparison group at 5 days. However, the change in BSES between 0 and 5 days was significantly greater in the intervention group compared with the comparison group (table 2). There was a group difference at 5 days in the increase in percentage of women only feeding by bottle $(7.5 \%$ increase for the intervention group and $15.5 \%$ increase for the control group)-see table 3 .
After the 5-day assessment, 35 of the comparison group requested a frenotomy, which was undertaken after counselling by the lactation consultants because the mothers were still having breastfeeding difficulties, and the infants' tongue-tie had not improved (no change in HATLFF score). Eight-week assessments were achieved on 52 (95\%) of the intervention group and $50(96 \%)$ of the comparison group, but only eight $(15 \%)$ of the comparison group had not had a frenotomy. Of these only five were feeding exclusively at the breast, one was mixed feeding, one was bottle feeding and one could not be contacted.

At 8 weeks, there were no differences between the groups in the breastfeeding measures or in infant weight (table 2). The changes in self-efficacy scores after frenotomy seen in the intervention group between 0 and 5 days were mirrored in the comparison group (most of whom had a frenotomy) between 5 days and 8 weeks (table 2). Table 3 shows that over $80 \%$ of both groups were still feeding at the breast at 8 weeks (Bristol average $58 \%)$.

Table 3 Method of feeding throughout the trial

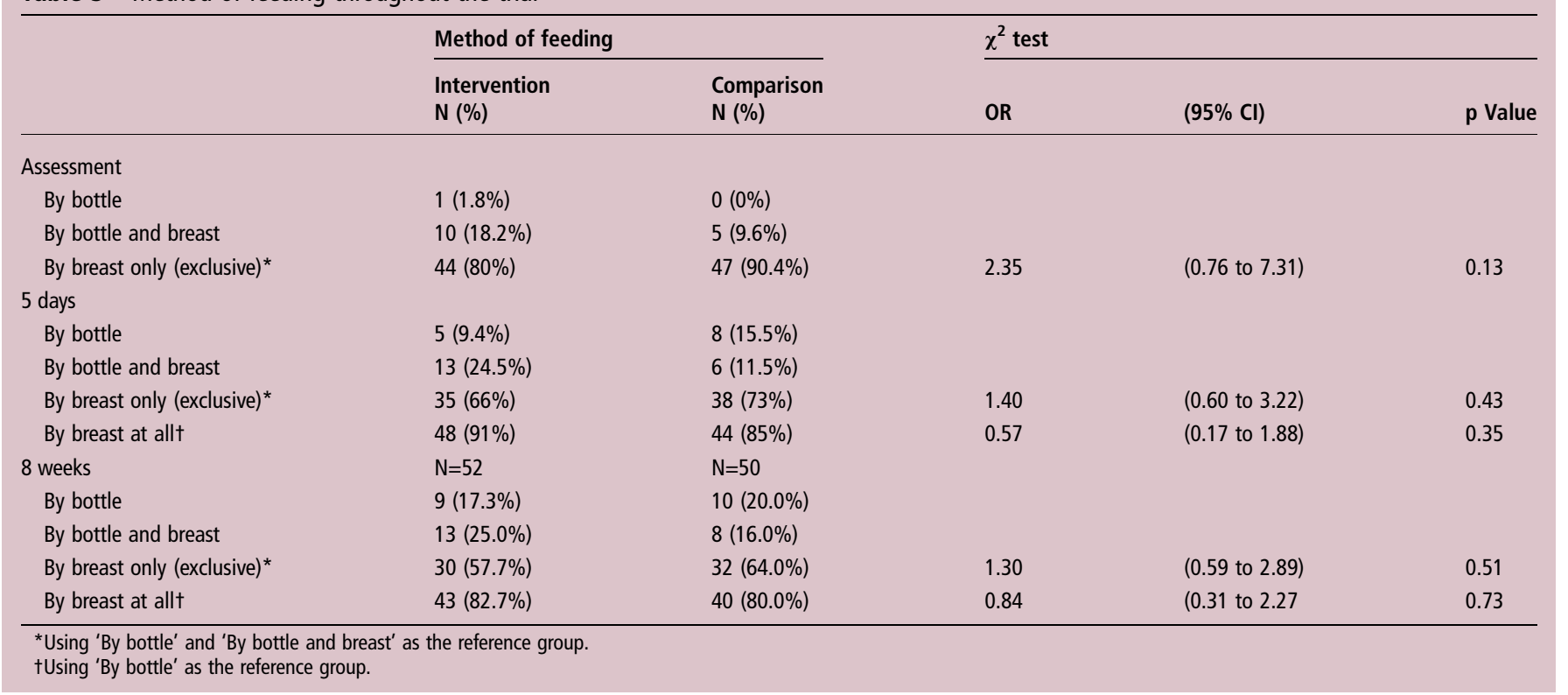




\section{Box 1 Reactions to frenotomy: 'immediate relief'}

"After the snip, it was immediately different, he seemed to be feeding much more efficiently. I'm really glad he got it done, it definitely helped immeasurably" (\#1: first baby, breast fed at 8 weeks).

"I was really struggling with feeding, having quite a lot of pain. After it was cut, the first feed immediately afterwards was certainly was one of the least painful ones I had done, and within a day or two it felt much better" (\#8: second baby, previous tongue-tie, breast fed at 8 weeks)

"I wanted to try anything I could that would help with feeding because I did not have a huge milk supply. He was having quite a lot of difficulty feeding and after it was cut he did definitely seem to feed better." (\#9: second baby, mixed fed at 8 weeks) "The soreness went quite quickly because he was not falling off and latching back on." (\#10: second baby, mixed fed at 8 weeks)

\section{Safety outcomes}

No adverse events were reported from the 102 mother/baby pairs who completed the trial (95\% CI 0 to 3.6). Out of 99 frenotomies, four $(4 \%)$ had to be repeated because the initial procedure did not divide sufficient frenulum. Out of 99 frenotomies, $63(64 \%)$ had a small white patch at the base of the frenulum reported by the mother at 5 days, and these took a median of 7 days (range 1-30 days) to heal.

\section{Results of interviews}

Twenty short interviews were conducted, seven with women in the intervention group and 13 in the comparison group. For 12, the baby in the trial was a first baby and for eight their second or subsequent baby. Ten were breastfeeding exclusively at 8 weeks, six were mixed feeding and four formula feeding; they lived in a range of 10 different postcode areas around Bristol.

\section{Box 2 Experience of being randomised to comparison} arm: 'frustration, disappointment, time to decide'

"The only thing I did not like about it (in control group) was that I then had 5 more days to sit and stress about it, I was getting myself worked up about it, the thought of someone cutting it. When it was done it was fine, she had a feed and she was fine." (\#4: second baby, formula feeding at 8 weeks) "Being randomised to control group, because it was only 5 days and it was over a weekend, I thought it would be ok, I think if it was two or three weeks or something it would have been hard to last and I would have thought twice." (\#10: second baby, mixed fed at 8 weeks)

"I was actually quite relieved because, as much as I thought it was a good idea to get it done, I also was afraid that it was going to be really painful for him. I was struggling to feed on one side more than the other, which was making it really sore. He was feeding quite often and that combined with his tongue-tie was just-was making things ten times worse. So after the 5 days, I thought if I wanted to carry on then it was worth giving it a go to see if it sort of improved the situation really." (\#16: 1st baby, formula fed at 8 weeks)
Box 3 Views of control mothers who decided not to request frenotomy: 'was it really needed?'

"..a little bit disappointed (randomised to comparison), but ..it made us think about whether it was needed. When we came back after 5 days we decided not to have it cut. I was coping fine, but also I don't really want to have things done unless you really need it." (\#15: first baby, breast fed at 8 weeks)

"We weren't sure whether we would be putting her in discomfort (by having it done). So when we went back after five days and the midwife did another assessment, she thought that the tongue-tie had improved a little bit and feeding wasn't causing me any pain anymore, so we decided not to put our daughter through anything that we didn't need to." (\#18: first baby, breast fed at 8 weeks)

All those interviewed had been happy to be approached to take part in the trial; they felt that being in the study had not delayed their treatment and that everything had seemed relevant and the service was fast. Most of those interviewed reported that they could feel a noticeable difference in how their baby fed immediately after the frenotomy had been done; it was not so painful and feeding also improved over the following few days. The mothers' reactions to having a frenotomy done are illustrated in box 1 .

The research team was interested in the mothers' experience of being randomised to the comparison arm and waiting for 5 days. While most interviewees from the comparison group expressed a degree of disappointment and frustration at being randomised to the non-intervention arm, others felt that it gave them more time to decide if frenotomy was really needed. They felt that 5-6 days was the most that they could have waited (see quotes in box 2). A few mothers in the comparison group decided not to have the frenotomy done at the 5-day appointment, but they were in the minority in the trial (see box 3).

\section{DISCUSSION}

This single centre randomised pragmatic trial has not been able to demonstrate an advantage for early frenotomy in improving breastfeeding difficulties in mild-moderate tongue-tie compared with waiting for 5 days. The study was successfully conducted, with excellent retention rates and high breastfeeding rates in both arms at the 8 -week end point. No safety concerns were raised about frenotomy. The trial has shown that it is feasible to explain equipoise about the role of frenotomy in mild-moderate tongue-tie to mothers who are experiencing breastfeeding difficulties, randomise them and to keep the majority of mothers in the non-intervention arm engaged until 5 days. However, 17\% in the comparison arm did not last to 5 days without demanding a frenotomy, and $15 \%$ switched to bottle feeding. The qualitative interviews indicated that 5 days was the limit that women were prepared to continue with painful and difficult feeding of a tongue-tied infant. Other smaller trials ${ }^{11} 14{ }^{15}$ of frenotomy have used outcomes at 24 or $48 \mathrm{~h}$, with follow-up to 3 months.

The tongue-ties did not resolve spontaneously, and after the primary outcome at 5 days, most women in the comparison group opted to have a frenotomy done. Of the mothers in the comparison group, only $12 \%$ were feeding their babies at the breast by 8 weeks without a frenotomy.

What we do not know, however, is how many women would have given up breastfeeding if frenotomy had been not been 
available in a few days' time; or how many women would have requested frenotomy if they were not aware a service existed. The trial hospital has good breastfeeding support from experienced lactation consultants, and midwives and mothers know that a frenotomy service is available. Half of the mothers who were eligible but refused randomisation wanted frenotomy straight away. Those randomised to the comparison arm knew that a frenotomy would be offered if they still had breastfeeding difficulties at 5 days.

The Bristol Tongue-Tie Trial encountered many of the issues with assessment of tongue-tie and breastfeeding reported by others. ${ }^{10}$ While the short HATLFF tool was able to categorise the severity of tongue-tie, it is based on subjective assessments and requires experience to apply consistently. ${ }^{16}$ The main limitation of this trial is that the measures used to assess breast feeding were relatively insensitive in picking up difficulties in attachment due to tongue-tie, even in the expert hands of the lactation specialists. This is in contrast to other studies that have shown improvements in LATCH scores ${ }^{2}$ or IBFAT scores. ${ }^{14}$ The self-efficacy tool, in which mothers rated their own confidence in breastfeeding, proved to be the best measure. Maternally rated self-efficacy has been shown to correlate well with overall duration of breastfeeding ${ }^{20} 21$ and self-efficacy has been an outcome in other trials of frenotomy. ${ }^{11}$

Painful nipples, due to inefficient sucking and frequent attempts to latch on to the breast, is a common complaint from mothers of tongue-tied babies and was a primary outcome measure in other studies. ${ }^{13}{ }^{24}$ While the simple VAS used in the Bristol Trial was not sensitive enough to show differences between the groups, the relief of painful sucking provided by frenotomy was a clear theme emerging from the qualitative interviews.

Simple inspection of a tongue-tie is not enough to determine which infants should be offered early frenotomy, and clinical assessment must include observation and measurement of the effectiveness of feeding. Better assessment tools are needed. ${ }^{9} 10$ There is a continuing need for lactation support even after a frenotomy to ensure breastfeeding is established and maintained. This trial, the largest so far reported, adds to the available evidence by showing that mild-moderate tongue-tie can be managed with breastfeeding support for 5 days but that if feeding is still difficult and painful at this point, then mothers want their babies to have a frenotomy-which is a safe and low-cost procedure.

In conclusion, tongue-tie is a common condition which is not easy to measure objectively, and its impact on feeding is complicated to assess. Although the majority of mothers of infants with mild-moderate tongue-tie were compliant for 5 days with the treatment arm to which they were allocated, this carefully conducted randomised trial could not demonstrate an objective and sustained improvement in breastfeeding following the procedure because the majority in the comparison arm ended up having the intervention.

Acknowledgements We thank the parents who took part in the trial, the midwives and the lactation support team for their help in recruiting and supporting breastfeeding mothers. The Bristol Tongue Tie Trial was overseen by an independent trial steering committee: Professor Paul Stallard (chair) Colin Powell, Mike Woolridge, Ann Remmers, Nina Stonelake and Heidi Evans.

Contributors AE was the local principal investigator for the trial, chaired the trial management committee, contributed to trial design, supervised data collection and analysis and contributed to data interpretation. He wrote the first draft of the paper and approved the final version of the manuscript. Jl was a member of the trial management committee, supervised data collection, undertook the qualitative interviews and contributed to analysis and data interpretation. She contributed to earlier drafts and approved the final version of the manuscript. DJ was the trial manager and a member of the trial management committee. She collected outcome data, prepared data files for analysis and contributed to data interpretation. She approved the final version of the manuscript. PB was the trial statistician and a member of the trial management committee. He undertook the analyses, contributed to data interpretation and approved the final version of the manuscript. AW was an expert member of the trial management committee. He contributed to trial design, data interpretation and approved the final version of the manuscript. MC was an expert member of the trial management committee. She assessed women for eligibility for the trial, undertook frenotomies and collected data, contributed to data interpretation and approved the final version of the manuscript. AS was the chief investigator for the trial and the grant holder with National Institute for Health Research. He was a member of the trial management committee, contributing to trial design, data interpretation and approved the final version of the manuscript.

Funding This independent research was funded by the National Institute for Health Research (NIHR) under its Research for Patient Benefit (RfPB) Programme (Grant Reference Number PB-PG-0110-21019). The views expressed are those of the authors and not necessarily those of the National Health Service (NHS), the NIHR or the Department of Health.

Competing interests None.

Ethics approval Central Bristol LREC.

Provenance and peer review Not commissioned; externally peer reviewed.

Data sharing statement All authors had full access to all of the data (including statistical reports and tables) in the study and can take responsibility for the integrity of the data and the accuracy of the data analysis.

Open Access This is an Open Access article distributed in accordance with the Creative Commons Attribution Non Commercial (CC BY-NC 3.0) license, which permits others to distribute, remix, adapt, build upon this work non-commercially, and license their derivative works on different terms, provided the original work is properly cited and the use is non-commercial. See: http://creativecommons.org/ licenses/by-nc/3.0/

\section{REFERENCES}

1 Ricke LA, Baker NJ, Diane J, et al. Newborn tongue-tie: prevalence and effect on breast-feeding. J Am Board Fam Pract 2005;8:1-7.

2 Ballard JL, Auer CA, Khoury JC. Ankyloglossia: assessment, incidence, and effect of frenuloplasty on the breastfeeding dyad. Pediatrics 2002;110:e63.

3 Segal L, Stephenson R, Dawes M, et al. Prevalence, diagnosis and treatment of ankyloglossia. Methodologic review. Can Fam Physician 2007;53:1027-33.

4 Ngerncham S, Laohapensang M, Wongvisutdhi T, et al. Lingual frenulum and effect on breastfeeding in Thai newborn infants. Paediatr Int Child Health 2013;33:86-90.

5 Griffiths DM. Do tongue-ties affect breastfeeding? J Hum Lact 2004;20:409-14.

6 Madlon-Kay DJ, Ricke LA, Baker NJ, et al. Case series of 148 tongue-tied newborn babies evaluated with the assessment tool for lingual frenulum function. Midwifery 2008;24:353-7.

7 Health and Social Care Information Centre. Infant Feeding Survey 2010. IFF research 2012. http://www.ic.nhs.uk

8 National Institute for Clinical Excellence (NICE) IPG149 (2005). Division of ankyloglossia (tongue-tie) for breastfeeding. http://www.nice.org.uk/IPG149

9 Hall D, Renfrew MJ. Tongue tie. Arch Dis Child 2005:90:1211-15.

10 Webb AN, Hao W, Hong P. The effect of tongue-tie division on breastfeeding and speech articulation: a systematic review. Int J Pediatr Otorhinolaryngol 2013;77:635-46

11 Hogan M, Westcott C, Griffiths M. A randomised controlled trial of division of tongue-tie in infants with feeding problems. J Paediatr Child Health 2005:41:246-50.

12 Heller J, Gabbay J, O'Hara C, et al. Improved ankyloglossia correction with four-flap Z-frenuloplasty. Ann Plast Surg 2005;54:623-8.

13 Dollberg $S$, Botzer $E$, Grunis $E$, et al. Immediate nipple pain relief after frenotomy in breast-fed infants with ankyloglossia: a randomized, prospective study. J Pediatr Surg 2006;41:1598-600.

14 Buryk M, Bloom D, Shope T. Efficacy of neonatal release of ankyloglossia: a randomized trial. Pediatrics 2011:128:280-8.

15 Berry J, Griffiths M, Westcott C. A double-blind, randomized, controlled trial of tongue-tie division and its immediate effect on breastfeeding. Breastfeed Med 2012;7:189-93.

16 Amir LH, James JP, Donath SM. Reliability of the Hazelbaker Assessment Tool for lingual frenulum function. Int Breastfeed J 2006;1:3-8.

17 Jenson D, Wallace S, Kelsay P. LATCH: a breastfeeding charting system and documentation tool. J Obstet Gynecol Neonatal Nurs 1994;23:29.

18 Matthews MK. Developing an instrument to assess infant breastfeeding behaviour in the early neonatal period. Midwifery 1988:4:54-65. 
19 Dennis CL. The breastfeeding self-efficacy scale: psychometric assessment of the short form. J Obstet Gynecol Neonatal Nurs 2003;32:734-44.

20 Baghurst $\mathrm{P}$, Pincombe J, Peat $\mathrm{B}$, et al. Breastfeeding self efficacy and other determinants of the duration of breastfeeding in a cohort of first-time mothers in Adelaide, Australia. Midwifery 2007:23:382-91.

21 Bandura A. Self-efficacy: toward a unifying theory of behaviour change. Psych Review 1977;84:191-215.
22 Gregory A, Penrose K, Morrison C, et al. Psychometric properties of the Breastfeeding Self-Efficacy Scale-short form in an ethnically diverse UK sample. Public Health Nurs 2000;5:278-84.

23 Silverman D. Doing qualitative research: a practical handbook. London: Sage publications, 2000.

24 Srinivasan A, Dobrich C, Mitnick H, et al. Ankyloglossia in breastfeeding infants: the effect of frenotomy on maternal nipple pain and latch. Breastfeed Med 2006;1:216-24. 